\title{
Synergistic effect of hyperbaric oxygen preconditioning and hydrogen-rich saline in ameliorating rat flap ischemia/reperfusion injury
}

\author{
Yi-Ding Xiao1, Yun-Qi Liư ${ }^{2}$, Ming-Zi Zhang ${ }^{1}$, You-Bin Wang ${ }^{1}$, Yi-Fang Liu², Xue-Mei Ma² \\ ${ }^{1}$ Department of Plastic Surgery, Peking Union Medical College Hospital, Dongcheng 100730, Beijing, China. \\ ${ }^{2}$ College of Life Science and Bioengineering, Beijing University of Technology, Chaoyang 100124, Beijing, China.
}

Address for correspondence: Dr. You-Bin Wang, Department of Plastic Surgery, Peking Union Medical College Hospital, Dongcheng 100730, Beijing, China. E-mail: wybenz@sina.com

\begin{abstract}
Aim: This study was conducted to evaluate the synergistic effects of hyperbaric oxygen (HBO) preconditioning and hydrogen-rich saline (HRS) treatment on skin flap survival and apoptosis in a rat ischemia/reperfusion (IR) skin flap model. Methods: Male Sprague-Dawley rats were randomly divided into five groups: one sham surgery group (sham group) and four surgery groups (IR group, $\mathrm{HBO}$ group, HRS group, and HBO + HRS group). An extended epigastric adipocutaneous flap $(6 \mathrm{~cm} \times 9 \mathrm{~cm})$ was raised over the abdomen in each animal of all five groups. The last four groups underwent $6 \mathrm{~h}$ of IR management and were treated, respectively, with normal saline, HBO, HRS (HRS, $0.8 \mathrm{mmol} / \mathrm{L}$ ), or a combined approach (HBO and HRS). On the 3rd postoperative day, flap survival rate and perfusion condition, apoptotic index, caspase-3 activity, protein expression of pASK1 and Bcl-2/Bax ratio, and Bcl-2 messenger RNA (mRNA) expression were assessed. Results: Prior studies have shown the protective effects of HBO and HRS, both of which have been associated with an increase in flap survival. Compared to the IR group, the flaps in the HBO, HRS, and HBO + HRS groups showed better perfusion and a larger survival area with a low number of apoptotic cells, low caspase-3 activity and pASK1 expression, and a high Bcl-2/Bax ratio and Bcl-2 mRNA expression. Of these groups, the $\mathrm{HBO}+\mathrm{HRS}$ group showed the best flap survival. Conclusion: Both HBO and HRS treatments increase the rate of flap survival, while the synergistic application of HBO and HRS showed a higher survival rate as compared to individual treatments of each. The potential regulation of apoptosis with the use of these two modalities may improve skin flap survival.
\end{abstract}

Key words:

Apoptosis, hydrogen-rich saline, hyperbaric oxygen, ischemia/reperfusion injury, skin flaps

\section{INTRODUCTION}

Although the transfer of skin flaps is widely used in wound coverage and reconstruction, soft tissue necrosis

\begin{tabular}{|l|l|}
\hline \multicolumn{2}{|c|}{ Access this article online } \\
\hline Quick Response Code: & Website: \\
\hline & www.parjournal.net \\
\hline & \\
\hline
\end{tabular}

remains a challenging problem. In a report by Chen et al., ${ }^{[1]}$ 113 cases $(9.9 \%)$ out of 1,142 free flap operations had

This is an open access article distributed under the terms of the Creative Commons Attribution-NonCommercial-ShareAlike 3.0 License, which allows others to remix, tweak, and build upon the work non-commercially, as long as the author is credited and the new creations are licensed under the identical terms.

For reprints contact: reprints@medknow.com

How to cite this article: Xiao YD, Liu YQ, Zhang MZ, Wang YB, Liu YF, Ma XM. Synergistic effect of hyperbaric oxygen preconditioning and hydrogen-rich saline in ameliorating rat flap ischemia/reperfusion injury. Plast Aesthet Res 2015;2:332-9.

Received: 24-04-2015; Accepted: 27-10-2015 
complications. Eighty-two percent of these 113 cases demonstrated some form of circulatory compromise within 24 h after surgery.

Postoperative hyperbaric oxygen (HBO) therapy has been used in plastic surgery in the treatment of random skin flaps, axial skin flaps, and flaps with survival problems with satisfactory results. ${ }^{[2,3]}$ The effect of HBO preconditioning has also been studied in many animal models including stroke $^{[4]}$ and spinal cord injury. ${ }^{[5]}$ In a study using a rat skin flap model, HBO preconditioning was found to improve skin flap survival and depress tumor necrosis factor- $\alpha$ (TNF- $\alpha)$ expression in skin tissue. ${ }^{[6]}$

In 2007, Ohsawa et al. ${ }^{[7]}$ reported that inhalation of $\mathrm{H}_{2}$ could selectively mitigate $\bullet \mathrm{OH}$ (oxhydryl), generating an antioxidant effect in a rat model of middle cerebral artery occlusion without affecting the signaling of other reactive oxygen species (ROS). Subsequently, $\mathrm{H}_{2}$ was shown to have protective effects on ischemic/reperfusion (IR) injury in various organs including the liver, heart, kidneys and small intestine. ${ }^{[8-11]}$ The authors have independently verified this protective effect. ${ }^{[12]}$

It is widely accepted that IR injury is a critical factor in flap failure while apoptosis is one important feature of the IR process. ${ }^{[13,14]}$ In this study, the synergistic effects of HBO preconditioning and hydrogen-rich saline (HRS) treatment were evaluated for their effects on skin flap survival and apoptosis in a rat IR skin flap model.

\section{METHODS}

\section{Animals}

All protocols were approved by the Committee on Animal Rights Protection of Peking Union Medical College Hospital and were in accordance with the National Institutes of Health guidelines for the care and use of laboratory animals. Adult male Sprague-Dawley (SD) rats weighing 280-320 g were used in this study. The rats were housed in individual cages under standard conditions with $22-25{ }^{\circ} \mathrm{C}$ and $12 \mathrm{~h}$ of a light-dark cycle. The rats were fed a normal diet with water provided ad lib pre- and post-operatively.

\section{Epigastric skin flap preparation}

An extended epigastric adipocutaneous flap $(6 \mathrm{~cm} \times 9 \mathrm{~cm})$ was raised over the abdomen in each animal. ${ }^{[12]}$ The left superficial epigastric artery and vein were ligated, and the right was retained as the pedicle. The pedicle artery and vein were occluded with a microvascular clamp and $6 \mathrm{~h}$ of skin flap ischemia was induced. The flap was then resutured with a silicone sheet of $0.1 \mathrm{~mm}$ deep to it to prevent neovascularization from the wound bed. The clamp was removed, and the flap was reperfused at the end of the ischemic period. Heparin $(50,000 \mathrm{U} / \mathrm{L}$ in $0.5 \mathrm{~mL}$ saline) was injected into the left epigastric artery to avoid thrombus formation prior to ligation.

\section{Hydrogen-rich saline production}

Hydrogen was dissolved in normal saline $(20 \mathrm{~mL})$ for $20 \mathrm{~min}$ with a speed of $0.2 \mathrm{~L} / \mathrm{min}$ to a supersaturated level. HRS was freshly prepared prior to each use, ensuring that a concentration of more than $0.8 \mathrm{mmol} / \mathrm{L}$ was reached by a needle-type $\mathrm{H}_{2}$ sensor (Unisense, Aarhus, Denmark).

\section{Experimental protocol and groups}

Fifty male SD rats were divided randomly into five groups with 10 animals in each group: (1) a sham-operated group (sham: no IR, HBO, HRS or normal saline injection). Rats in the sham group underwent the same surgery as the rats in the other four groups but without the period of ischemia; (2) IR group: $6 \mathrm{~h}$ of ischemia was induced by clamping the right pedicle, followed by an injected intraperitoneally of $5 \mathrm{~mL} / \mathrm{kg}$ normal saline, $10 \mathrm{~min}$ prior to reperfusion; (3) HRS-treated group: $6 \mathrm{~h}$ of ischemia was induced by clamping the right pedicle, followed by an intraperitoneally injection of $5 \mathrm{~mL} / \mathrm{kg}$ HRS, 10 min prior to reperfusion; (4) HBO group: $6 \mathrm{~h}$ of ischemia was induced by clamping the right pedicle after $\mathrm{HBO}$ preconditioning for 4 times; and (5) HBO and HRS group: $6 \mathrm{~h}$ of ischemia was induced by clamping the right pedicle after HBO preconditioning for 4 times. $5 \mathrm{~mL} / \mathrm{kg}$ HRS was administered by an intraperitoneally injection, 10 min prior to reperfusion.

\section{Hyperbaric oxygen preconditioning}

Rats in the HBO and HBO + HRS groups were treated with HBO 2 days before surgery. Treatment included HBO exposure 4 times for $60 \mathrm{~min}$ every $12 \mathrm{~h}$ (total exposure time of $4 \mathrm{~h}$ ). $2 \mathrm{~L} / \mathrm{min}$ of $100 \%$ oxygen was supplied continuously at $0.25 \mathrm{MPa}$ during the HBO treatment. Compression and decompression were performed at $5 \mathrm{psi} / \mathrm{min}$. The time at which the $\mathrm{HBO}$ chamber pressure reached $0.25 \mathrm{MPa}$ and remained stable was recorded. Calcium carbonate crystals were placed in the chamber to prevent $\mathrm{CO}_{2}$ accumulation. Flap surgery began $2 \mathrm{~h}$ following the final HBO treatment.

\section{Skip flap survival and perfusion evaluation}

Skin flap survival was evaluated $72 \mathrm{~h}$ after reperfusion by general observation of survival and necrotic phenomena and subsequently confirmed by laser speckle contrast analysis cameras (Perimed AB, Stockholm, Sweden). The surviving and necrotic areas were measured. The percentage of flap survival was defined as the ratio of the surviving area to the original flap area.

To evaluate skin flap perfusion, the rats were secured onto the operative bed such that the entire flap, including part of the normal abdominal skin, was exposed. The PeriScan PSI system (Perimed AB, Stockholm, Sweden) was positioned above the rats, imaging an area of $11 \mathrm{~cm} \times 7.5 \mathrm{~cm}$. The image acquisition rate was $3 \mathrm{~Hz}$ and lasted for $3 \mathrm{~min}$. The ambient temperature was maintained between $22{ }^{\circ} \mathrm{C}$ and $25{ }^{\circ} \mathrm{C}$ during this process. Perfusion of the necrotic and survival areas was analyzed. Vascular flow was measured using perfusion units (PUs).

Rats were sacrificed on the 3rd postoperative day with overdose anesthesia after skin flap survival and perfusion evaluation. The survival flaps were harvested for sampling.

TdT-mediated dUTP-X nick end labeling staining and apoptotic index evaluation

Tissue samples $\left(1 \mathrm{~cm}^{2}\right.$ in size) were taken from the proximal areas of the harvested flaps. Samples were sectioned into 
smaller pieces and fixed with $4 \%$ paraformaldehyde in $0.1 \mathrm{~mol} / \mathrm{L}$ phosphate buffer. They were then embedded in paraffin, sectioned and mounted onto slides for TdT-mediated dUTP-X nick end labeling (TUNEL) staining.

TUNEL staining was performed using an in situ cell death detection kit (Roche, Basel, Switzerland). After being heated to $60{ }^{\circ} \mathrm{C}$ and dewaxed, the sections were rehydrated and then incubated in a $20 \mu \mathrm{g} / \mathrm{mL}$ proteinase $\mathrm{K}$ working solution for $15 \mathrm{~min}$ at room temperature. The slides were rinsed ( $5 \mathrm{~min}, 3$ times) with phosphate-buffered saline (PBS) and then incubated in a TUNEL reaction mixture for $1 \mathrm{~h}$ at $37{ }^{\circ} \mathrm{C}$. The slides were rinsed once again and dried. Converter-POD (anti-fluorescein antibody, Fab fragment from sheep, and conjugated with peroxidase (POD)) was added to the samples for $1 \mathrm{~h}$ at $37{ }^{\circ} \mathrm{C}$. The sections were rinsed with PBS and stained with 3,3'-N-diaminobenzidine tetrahydrochloride. Five slide fields were randomly examined using a defined rectangular field area under $\times 40$ magnification. Cells were then counted under $\times 400$ magnification. The apoptotic index (AI) was represented as the percentage of TUNEL-positive cells versus the total number of cell nuclei per field.

\section{Caspase- 3 activity assay}

Caspase-3 activity was detected using a Fluorometric Assay Kit (Biovision Research Products, Mountain View, CA, USA). Briefly, $50 \mathrm{mg}$ of skin flap tissue was homogenized in $\times 2$ reaction buffer and incubated for $1 \mathrm{~h}$ at $37{ }^{\circ} \mathrm{C}$ with caspase-3 substrate (DEVD-APC, $1 \mathrm{mM}$ ). Substrate cleavage was measured with a spectrofluorometer at $400 \mathrm{~nm}$.

\section{ASKI and Bcl-2/Bax Western blot}

Skin flap tissue $(100 \mathrm{mg}$ ) was sampled from the proximal, middle and distal regions of the harvested flaps. The samples used for detection were randomly selected from all the samples in each rat in each group to avoid any deviation caused by using different parts of the skin flap samples. Ninety micrograms of total protein were extracted and analyzed from each sample. The protein samples were mixed with loading buffer and boiled at $95{ }^{\circ} \mathrm{C}$ for $15 \mathrm{~min}$. The protein samples were then electrophoresed in a $10 \%$ dodecyl sulfate-polyacrylamide gel (Bio-Rad, USA) and transferred onto nitrocellulose filter membranes for $1 \mathrm{~h}$ at $80 \mathrm{~V}$. The samples were incubated overnight at $4{ }^{\circ} \mathrm{C}$ with goat polyclonal actin antibody (1:1,000 dilution, Santa Cruz Biotechnology, Inc., USA), pASK1 antibody (1:500 dilution Cell Signaling Technology, Boston, MA, USA), rabbit anti-Bcl-2 polyclonal antibody (1:1,000 dilution, Chemicon International, Inc., USA), and rabbit anti-Bax polyclonal antibody (1:1,000 dilution, Stressgen Bioreagents, Corp., USA). The proteins were then incubated with horseradish peroxidase-conjugated secondary antibodies diluted at $1: 2,500$ for $1 \mathrm{~h}$ at $37^{\circ} \mathrm{C}$. The blots were then treated with a chemiluminescence detection reagent (Pierce, USA) and exposed to autoradiography film. The bands were then quantified by densitometry.

\section{Quantitative real-time polymerase chain reaction} for Bcl-2 messenger RNA

Skin flap tissue $(30 \mathrm{mg}$ ) was sampled from the proximal, middle and distal areas of the harvested flaps from each group. The total RNA was extracted from the samples using an RNeasy Fibrous Tissue Mini Kit (Qiagen, Düsseldorf, Germany). One microgram of total RNA was then reversely transcribed into single-stranded complementary DNA with a ProtoScript M-MuLV First Strand cDNA Synthesis Kit (New England Biolabs, Ipswich, MA, USA), according to the manufacturer's instructions. The complementary DNA was then used for real-time polymerase chain reaction (PCR). The process of amplification and quantification were performed with a real-time quantitative PCR system (Agilent, Santa Clara, CA, USA). $\beta$-actin was used as the internal control. The PCR protocol was as follows: heating for $2 \mathrm{~min}$ at $50{ }^{\circ} \mathrm{C}$, initialization at $95{ }^{\circ} \mathrm{C}$ for $10 \mathrm{~min}$, followed by 40 cycles of denaturation at $95{ }^{\circ} \mathrm{C}$ for $15 \mathrm{~s}$, annealing at $58{ }^{\circ} \mathrm{C}$ for $30 \mathrm{~s}$, and extension at $72{ }^{\circ} \mathrm{C}$ for $30 \mathrm{~s}$. The primers used in quantitative real-time PCR were Rat Bcl-2 (forward: 5'-AGAACCTTGTGTGACAAATGAGAA-3' and reverse: 5'-TACCCATTAGACA-TATCCAGCTTGA-3') and $\beta$-actin (forward: 5'-GGCGGCCAAACAGAAAG-3'and reverse: 5'-CTGAGGGCACGGAGGAT-3').

\section{Statistical analysis}

In this study, all data are reported as the mean \pm standard error of the mean (SEM). Significant differences were determined via one-way analysis of variance. Least significant difference $t$-test was used for between-group comparisons. Statistical significance was set at $P<0.05$. All analyses were conducted using SPSS 17.0 (SPSS Inc., Chicago).

\section{RESULTS}

\section{Skin flap survival}

Seventy-two hours following reperfusion, necrotic skin flaps were observed and presented as gray areas with little elasticity. In contrast, surviving areas maintained normal elasticity and skin color [Figure 1a]. The highest skin flap survival percentage was observed in the $\mathrm{HBO}+\mathrm{HRS}$ group $(47.70 \% \pm 12.05 \%)$. There were significant differences between the IR $(23.30 \pm 6.49 \%)$, HRS $(36.90 \% \pm 7.46 \%)$, HBO $(39.00 \% \pm 9.14 \%)$ and HBO + HRS $(47.70 \% \pm 12.05 \%)$ groups (values are the mean \pm SEM, IR vs. HRS, $P<0.01$; IR vs. HBO, $P<0.001$; IR vs. HBO + HRS, $P<0.001)$. Among the HBO, HRS and $\mathrm{HBO}+\mathrm{HRS}$ groups there were significant differences between HBO and HBO + HRS $(P<0.05)$, and HRS and HBO + HRS groups $(P<0.05)$ [Figure $1 \mathrm{~b}$ ].

\section{Skin flap perfusion evaluation}

Seventy-two hours following reperfusion, skin flap perfusion stabilized and was analyzed. Skin flap perfusions were $131.10 \mathrm{PU} \pm 20.14 \mathrm{PU}$ in the sham group, 26.10 PU \pm 8.09 PU in the IR group, 62.40 PU \pm 14.10 PU in the HBO group, 56.00 PU $\pm 25.12 \mathrm{PU}$ in the HRS group and $84.70 \mathrm{PU} \pm 13.44 \mathrm{PU}$ in the $\mathrm{HBO}+\mathrm{HRS}$ group.

A significantly higher blood perfusion was measured in the sham, HBO and HBO + HRS groups. There were statistical differences between the following groups: IR $v s$. HBO, $P<0.001$; IR vs. HRS, $P<0.001$; IR vs. HBO + HRS, $P<0.001$; HRS vs. HBO + HRS, $P<0.01$; and HBO vs. HBO + HRS, $P<0.01$ [Figure $1 \mathrm{c}$ ]. 


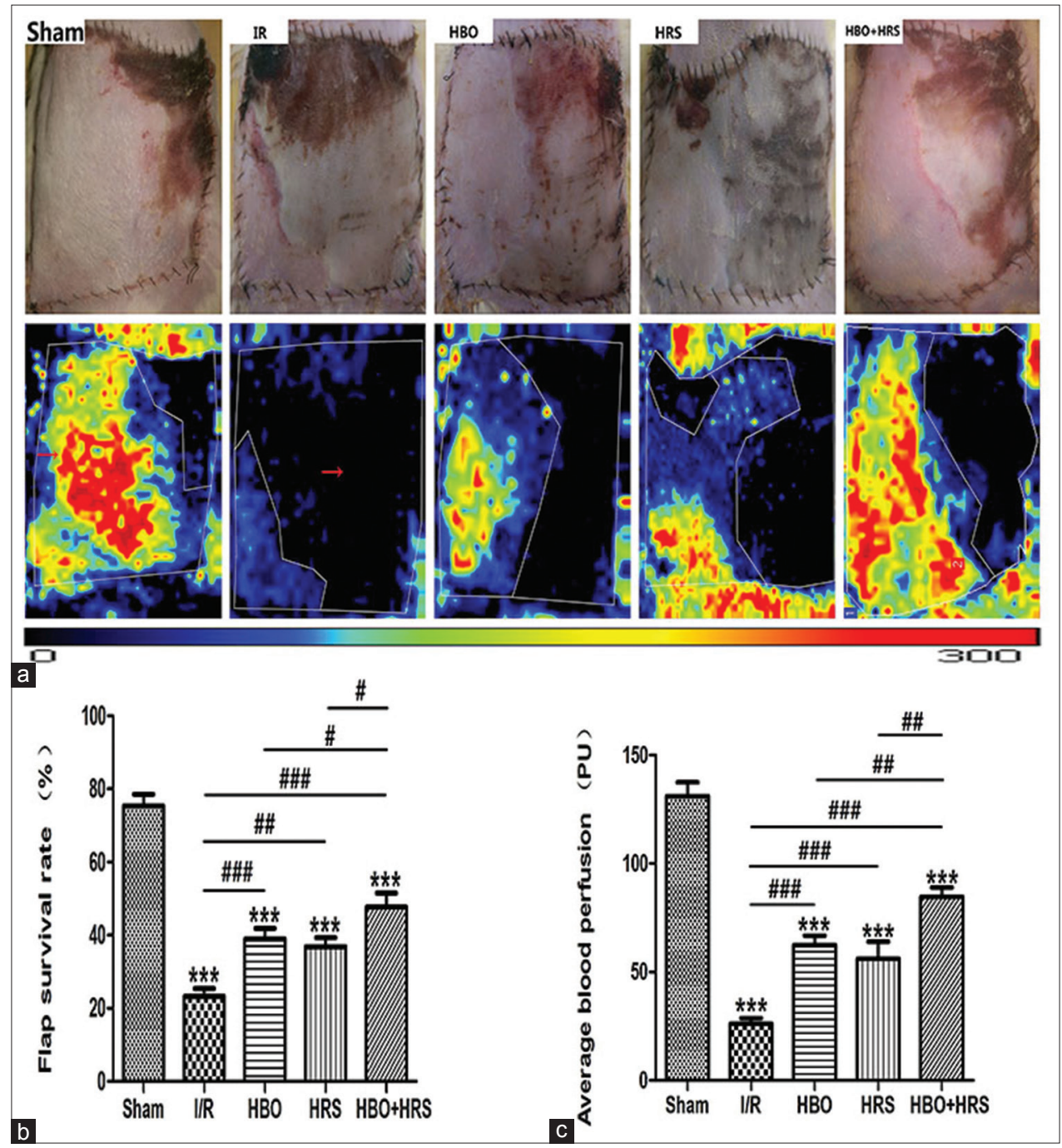

Figure 1: The evaluation of the abdominal skin flaps $72 \mathrm{~h}$ following ischemia-reperfusion. Black zones represent the necrotic areas. Red, yellow, and the adjacent blue areas represent surviving areas with rich blood perfusion. (a) Representative photographs of abdominal skin flap microcirculation in the five groups are shown; (b) the survival rate of the total flap area. Flap survival rates were markedly higher in the hyperbaric oxygen, hydrogen-rich saline, and hyperbaric oxygen + hydrogen-rich saline groups; (c) the average blood perfusion of total skin flaps. The hyperbaric oxygen + hydrogen-rich saline group has the greatest blood perfusion among the surgery groups. IR: ischemia reperfusion, HBO: postoperative hyperbaric oxygen, HRS: hydrogen-rich saline

\section{Apoptotic index evaluation}

Apoptotic cell death was observed with TUNEL staining [Figure 2a]. The number of apoptotic cells increased in the IR group $(45.85 \% \pm 6.64 \%)$ as compared with the sham group $(8.57 \% \pm 4.12 \%)$. Apoptotic cell number was reduced with $\mathrm{HBO}$ preconditioning, HRS and HRS and $\mathrm{HBO}$ preconditioning used cooperatively. HRS and HBO preconditioning used cooperatively were more efficient in reducing cell apoptotic death than that of HBO preconditioning or HRS used independently. The AI in HRS was $32.69 \% \pm 6.80 \%$, in the HBO group was $30.80 \% \pm 7.13 \%$, and in the HBO + HRS group was $20.24 \% \pm 6.90 \%$. There were significant differences between each surgical group, (IR vs. HBO, $P<0.001$; IR vs. HRS, $P<0.001$; IR vs. HBO + HRS, $P<0.001$; HBO vs. HBO + HRS, $P<0.01$; and HRS vs. HBO + HRS, $P<0.001$ ) with the exception of HBO versus HRS [Figure $2 b$ ].

\section{Caspase- 3 activity}

Compared to the IR group (1.25 \pm 0.26$)$, the caspase-3 relative activity was significantly lower in the HBO $(0.59 \pm 0.12)$, HRS $(0.53 \pm 0.15)$, and
HBO + HRS $(0.36 \pm 0.17)$ groups IR $(P<0.001)$. Significant differences between the HBO + HRS group and the HBO and HRS groups were also found (HBO + HRS vs. HRS, $P<0.05$; HBO + HRS vs. HBO, $P<0.01$ ). However, there was no statistical difference between the HBO and HRS groups [Figure 3].

\section{Western blot for pASKI and Bcl-2/Bax}

The protein expression of pASK1, Bcl-2 and Bax proteins was analyzed by Western blot [Figure 4a]. pASK1 expressed the highest level in the IR group $(0.25 \pm 0.04)$ compared with other groups and was significantly decreased in the HBO + HRS group $(0.13 \pm 0.05)$ as compared to the IR $(0.25 \pm 0.04)$, HRS $(0.17 \pm 0.04)$ and HBO $(0.18 \pm 0.03)$ groups. Statistical differences were observed in HBO + HRS vs. IR, $P<0.001$; HRS vs. IR, $P<0.001$; HBO vs. IR, $P<0.001$; HBO + HRS vs. HBO, $P<0.05$; and HBO + HRS vs. HRS, $P<0.05$ [Figure 4b].

The ratio between the level of $\mathrm{Bcl}-2$ to Bax expression increased in the HBO $(2.06 \pm 0.49)$, HRS $(2.90 \pm 0.65)$ and HBO + HRS $(3.27 \pm 0.42)$ groups. The $\mathrm{Bcl}-2 / \mathrm{Bax}$ 


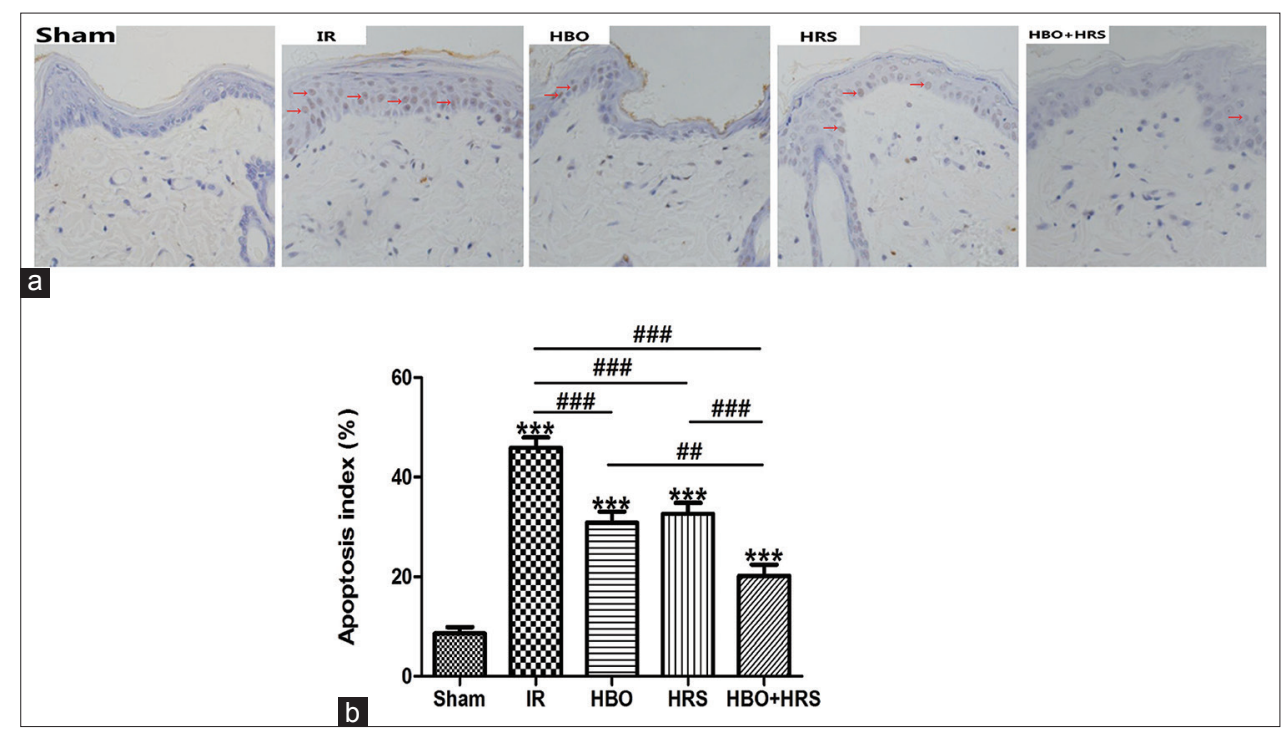

Figure 2: The results of TdT-mediated dUTP-X nick end labeling staining and the apoptosis index $72 \mathrm{~h}$ following ischemia-reperfusion. (a) The evaluation of apoptotic cell death by TdT-mediated dUTP-X nick end labeling staining in all groups. Apoptotic cell number was reduced with hyperbaric oxygen preconditioning, hydrogen-rich saline and hydrogen-rich saline and hyperbaric oxygen preconditioning used cooperatively (brown staining indicates apoptotic cells [red arrow]; $\times 200$ ); (b) the apoptosis index of all groups. The data shown indicate the percentage of TdT-mediated dUTP-X nick end labeling-positive cells and the total cell nuclei per field. Three different slide fields from different skin tissues were counted. TUNEL: TdT-mediated dUTP-X nick end labeling, IR: ischemia reperfusion, HBO: postoperative hyperbaric oxygen, HRS: hydrogen-rich saline

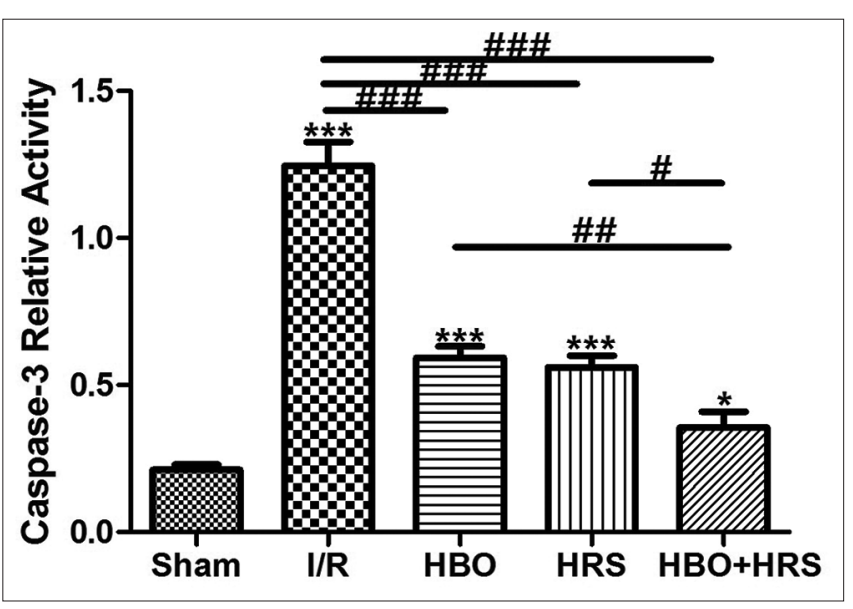

Figure 3: Caspase-3 activity in all groups $72 \mathrm{~h}$ following ischemia-reperfusion. Compared to the ischemia-reperfusion group, caspase-3 activity was significantly inhibited in the hyperbaric oxygen, hydrogen-rich saline, and hyperbaric oxygen + hydrogen-rich saline groups. IR: ischemia reperfusion, HBO: postoperative hyperbaric oxygen, HRS: hydrogen-rich saline

ratio in the IR group $(0.98 \pm 0.40)$ was the lowest. Statistical differences were observed between $\mathrm{HBO}+$ HRS vs. IR, $P<0.001$; HBO vs. IR, $P<0.001$; HRS vs. IR, $P<0.001$; HRS vs. HBO, $P<0.001$; and HBO + HRS vs. HBO, $P<0.001$. The highest $\mathrm{Bcl}-2 / \mathrm{Bax}$ ratio was in the $\mathrm{HBO}+\mathrm{HRS}$ group, but there was no significant difference between the HBO + HRS and HRS groups [Figure 4c].

\section{Bcl-2 messenger RNA expression}

The messenger RNA (mRNA) levels in each group were determined with real-time PCR. $\beta$-actin was used as a reference gene. Among all groups, the IR group $(0.03 \pm 0.03)$ showed the lowest level of Bcl-2 mRNA expression with the exception of the sham group. Among surgery groups, there were significant differences between the IR group and other groups (IR vs. HBO, $P<0.01$; IR vs. HRS, $P<0.001$; IR vs. HBO + HRS,
$P<0.001)$. The expression of $\mathrm{Bcl}-2$ mRNA in the HBO + HRS group $(0.15 \pm 0.05)$ was higher than in the HBO group $(0.08 \pm 0.03)$ and HRS group $(0.11 \pm 0.05)$, with statistically significant differences (HBO + HRS vs. HBO, $P<0.001$; HBO + HRS vs. HRS, $P<0.05$ ) [Figure 5].

\section{DISCUSSION}

Flap transfer has become a basic albeit challenging technique for all plastic surgeons given the high-risk of flap failure. Even in cases of microsurgical transfer with a stable blood supply, skin flap loss still ranges between $1 \%$ and $5 \%$ in experienced hands. ${ }^{[12,15]}$ There are many reasons for partial or total flap loss, including IR injury. During the process of IR injury, flap cells may change their biochemical properties with the induction of apoptosis, ${ }^{16]}$ cell shrinkage, ${ }^{[17]}$ nuclear condensation, and cell death, ${ }^{[18-20]}$ leading to flap loss.

In clinical work, HBO has been widely used in the treatment of challenging wounds and selected neurological diseases. HBO is considered to be a successful adjunctive therapy for wound healing. In the plastic field, postoperative HBO treatment is commonly used following flap transfer with satisfactory improvement. There has also been research into the protective effect of $\mathrm{HBO}$ therapy through preconditioning. Cheng found that HBO reduced cyclooxygenase- 2 expression and provided brain protection following ischemia. ${ }^{[4]}$ The current authors have also examined the effects of $\mathrm{HBO}$ preconditioning in a rat skin flap model and found an improvement in flap survival in IR injuries. The mechanisms responsible for its protective effect may be related to attenuation of the inflammatory response and increased flap perfusion. ${ }^{[6]}$

Recently, other therapeutic gasses have been studied, in particular, hydrogen. Hydrogen can reach relatively 


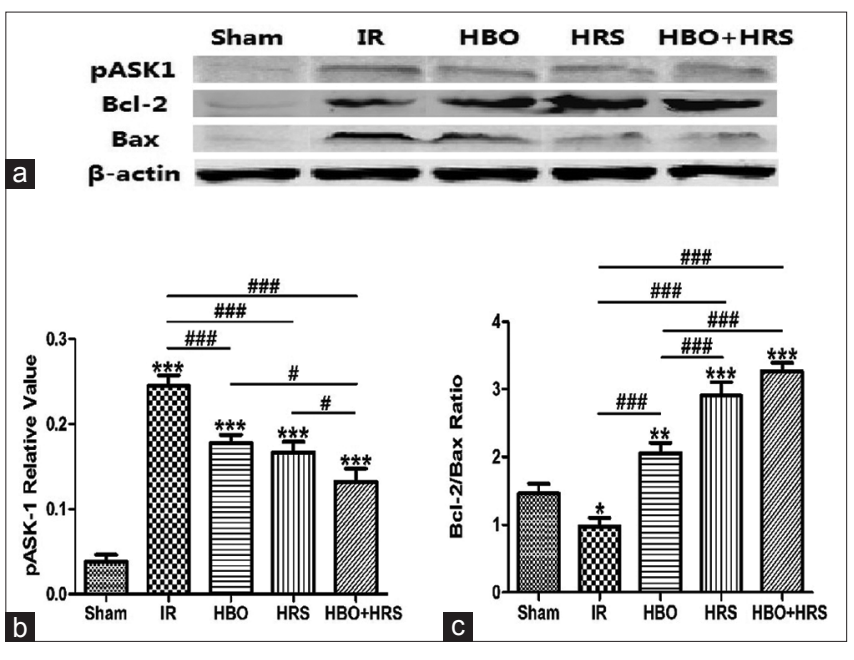

Figure 4: The results of Western blot, pASK1 relative value and $\mathrm{Bcl}-2 / \mathrm{Bax}$ ratio in each group $72 \mathrm{~h}$ following ischemia-reperfusion. (a) Representative images of Western blots for pASK1, Bcl-2, and Bax; (b) pASK1 relative values in all groups. Compared to the ischemia-reperfusion group, the expression of pASK1 was significantly reduced in the hyperbaric oxygen, hydrogen-rich saline, and hyperbaric oxygen + hydrogen-rich saline groups; (c) the ratio between $\mathrm{Bcl}-2$ and Bax in all groups. Bcl-2/ Bax ratio reveals the highest level in hyperbaric oxygen + hydrogen-rich saline group. IR: ischemia reperfusion, HBO: postoperative hyperbaric oxygen, HRS: hydrogen-rich saline

high concentrations quickly, and excessive hydrogen can be eliminated from the body via breathing, leaving no side effects. ${ }^{[21]}$ The protective and therapeutic effects of hydrogen in humans have been reported and include such applications as diabetes mellitus type II, ${ }^{[2]}$ hemodialysis, ${ }^{[23]}$ inflammatory myopathies, ${ }^{[24]}$ radiotherapy for liver cancer, ${ }^{[25]}$ and acute erythematous skin diseases. ${ }^{[26]}$ Animal research in the rat skin flap model has also been performed to test the protective effect of HRS and has shown that HRS increases the surviving areas of rat abdominal skin flaps while decreasing oxidative stress and inflammation. ${ }^{[12]}$

Based on the above theories, this study focused on the combined application of HBO preconditioning and HRS treatment, demonstrating its synergistic effect in protecting a rat skin flap from IR injury by depressing apoptosis. In this study, an abdominal island skin flap IR model was established by ligating the left superficial epigastric artery to investigate cellular and molecular changes following HBO, HRS, and combined treatments. This model was first established by Kuntscher et al. ${ }^{[27]}$ In his study, an extended $(6 \mathrm{~cm} \times 10 \mathrm{~cm})$ epigastric adipocutaneous flap was harvested, and then the flap was sutured back over a silicone sheet. This flap model has been widely used to study IR injury for the following reasons: first, the flap size is large enough for observation of the survival area. In the sham group, the epigastric artery could only sustain $75.40 \% \pm 10.01 \%$ of the blood supply to the flap; second, with a large flap size, the survival area in each group can be measured scientifically and easily compared. Second, in this model, the flap was supplied by one epigastric artery while other was ligated. A silicon sheet was also used to prevent revascularization. Thus, the blood supply to the model can be easily controlled and manipulated. In this study, several modifications were made including

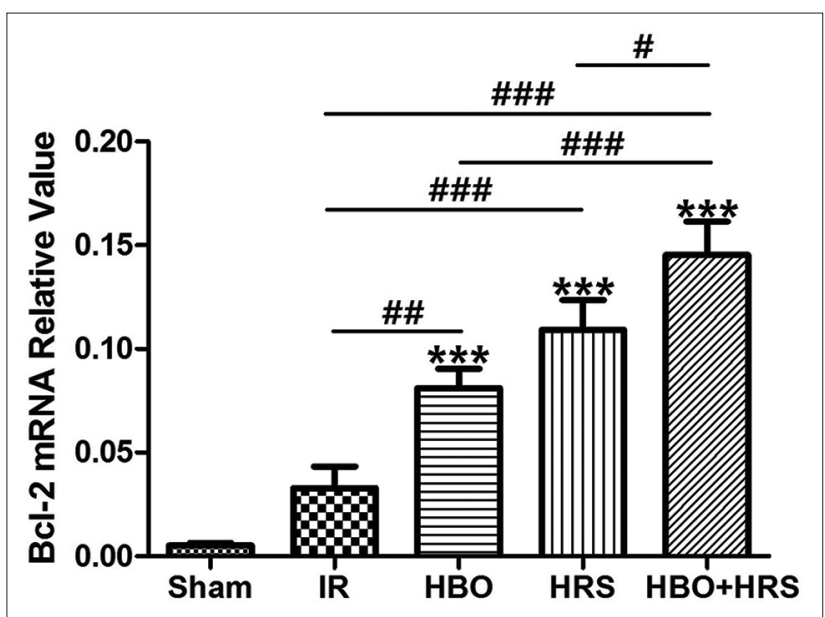

Figure 5: The relative value of $\mathrm{Bcl}-2$ messenger RNA in all groups $72 \mathrm{~h}$ following ischemia-reperfusion. Compared to the ischemia-reperfusion group, the hyperbaric oxygen, hydrogen-rich saline, and hyperbaric oxygen + hydrogen-rich saline groups show higher levels of $\mathrm{Bcl}-2$ messenger RNA expression, especially the hyperbaric oxygen + hydrogen-rich saline group. IR: ischemia reperfusion, HBO: postoperative hyperbaric oxygen, HRS: hydrogen-rich saline

the use of an ultrathin silicon sheet $(0.1 \mathrm{~mm})$ to avoid revascularization and heparinized saline to avoid thrombus formation. ${ }^{[12]}$ Analysis of the results showed that skin flaps with HBO preconditioning and HRS treatment have the highest rate of survival in an IR model.

As a new mechanism of inducing cellular IR injury, a TNF- $\alpha$-induced inflammation via mitochondrial ROS (mtROS) generation has received much attention. mtROS generated by TNF- $\alpha$ can oxidize the reduced thioredoxin-apoptosis signal-regulating kinase 1 complex (Trx [SH] 2-ASK1), and then activate ASK1 and its downstream stress signaling targets including $\mathrm{JNK}^{[28-31]}$ to initiate apoptosis. ASK1 could, therefore, be considered to be a bridge during the apoptotic signaling pathway. One pair of proteins plays a paramount role in regulating apoptosis, specifically the antiapoptotic protein $\mathrm{Bcl}-2$ and the pro-apoptotic protein Bax. The ratio of $\mathrm{Bcl}-2 / \mathrm{Bax}$ determines the cellular direction toward apoptosis. ${ }^{[32]}$ Caspase-3 plays an important role in increasing the rate of apoptosis. Activated caspase- 3 cuts poly (ADP-ribose) polymerase and increase the activity of $\mathrm{Ca}^{2+} / \mathrm{Mg}^{2+}$-dependant endonuclease to destroy DNA molecules. ${ }^{[33]}$

In this study, the HBO, HRS and HBO + HRS groups showed low levels of apoptotic. HBO preconditioning and HRS used cooperatively were more efficient in reducing cellular apoptosis than HRS or HBO preconditioning used independently. Caspase-3 could increase the rate of apoptosis. ASK1, as a bridge in the apoptotic process, determines the integrity of the JNK pathway. The caspase-3 activity and pASK1 expression were significantly reduced in the HBO, HRS and HBO + HRS groups. Compared to the HBO and HRS groups, the HBO + HRS group showed the lowest level of caspase-3 activity and pASK1 expression. $\mathrm{Bcl}-2$, a mitochondrial anchoring protein, may prevent apoptosis by acting as an antioxidant. ${ }^{[3]}$ The Bcl-2/Bax ratio and $\mathrm{Bcl}-2$ mRNA expression were increased among the HBO, HRS and HBO + HRS groups. The Bcl-2/Bax 
ratio and $\mathrm{Bcl}-2$ mRNA expression level were higher in the HBO + HRS group than in the HBO or HRS groups.

This study demonstrates the synergistic effect of HBO preconditioning and HRS treatment. By combining the advantages of HBO and HRS, improved flap survival and ischemia tolerance can be used clinically. IR oxygen is not a rare gas and can be readily accessed. However, the application of hydrogen is challenging secondary to its explosive properties and the difficulty of transportation. HRS avoids such problems and can be used in many clinical scenarios. The mechanism of the synergistic effect of HBO preconditioning and HRS treatment have not yet been fully elucidated, and further studies are required. A limitation of this study was the need for an additional IR group with a placebo treatment which would have allowed the comparison of the effects of HBO treatment. With this group, the study would have been more rigorous.

This study showed that compared to an IR group, the rate of skin flap survival is improved, and cellular apoptosis is attenuated secondary to a synergistic effect of HBO preconditioning and HRS treatment.

In conclusion, the synergistic application of $\mathrm{HBO}$ and HRS showed a higher flap survival rate, which could be a combined treatment to improve skin flap survival against IR injury.

\section{Financial support and sponsorship}

Project supported by the National Natural Science Foundation of China (No. 81171874) and the Beijing Natural Science Foundation (No. 7132169).

\section{Conflicts of interest}

There are no conflicts of interest.

\section{REFERENCES}

I. Chen KT, Mardini S, Chuang DC, Lin CH, Cheng MH, Lin YT, Huang WC, Tsao CK, Wei FC. Timing of presentation of the first signs of vascular compromise dictates the salvage outcome of free flap. Plast Reconstr Surg 2007; 120:187-95.

2. Zhang T, Gong W, Li Z, Yang S, Zhang K, Yin D, Xu P, Jia T. Efficacy of hyperbaric oxygen on survival of random pattern skin flap in diabetic rats. Undersea Hyperb Med 2007;34:335-9.

3. Al-Liethy IM, Hanafy AA, Abdel-Aal M, Zaki B. The effect of an extended protocol of hyperbaric oxygen therapy $(\mathrm{HBO})$ on the rat TRAM fap model. Egypt J Plast Reconstr Surg 2007;3 I:7-I3.

4. Cheng O, Ostrowski RP, Wu B, Liu W, Chen C, Zhang JH. Cyclooxygenase-2 mediates hyperbaric oxygen preconditioning in the rat model of transient global cerebral ischemia. Stroke 201 I;42:484-90.

5. Dong H, Xiong L, Zhu Z, Chen S, Hou L, Sakabe T. Preconditioning with hyperbaric oxygen and hyperoxia induces tolerance against spinal cord ischemia in rabbits. Anesthesiology 2002;96:907-I2.

6. Qi Z, Gao CJ, Wang YB, Ma XM, Zhao L, Liu FJ, Liu XH, Sun XJ, Wang XJ. Effects of hyperbaric oxygen preconditioning on ischemia-reperfusion inflammation and skin flap survival. Chin Med J (Engl) 20I3; I26:3904-9.

7. Ohsawa I, Ishikawa M, Takahashi K, Watanabe M, Nishimaki K, Yamagata K, Katsura K, Katayama Y, Asoh S, Ohta S. Hydrogen acts as a therapeutic antioxidant by selectively reducing cytotoxic oxygen radicals. Nat Med 2007; 13:688-94.

8. Fukuda K, Asoh S, Ishikawa M, Yamamoto Y, Ohsawa I, Ohta S. Inhalation of hydrogen gas suppresses hepatic injury caused by ischemia/reperfusion through reducing oxidative stress. Biochem Biophys Res Commun 2007;361:670-4.
9. Nakao A, Kaczorowski DJ, Wang Y, Cardinal JS, Buchholz BM, Sugimoto R, Tobita K, Lee S, Toyoda Y, Billiar TR, McCurry KR. Amelioration of rat cardiac cold ischemia/reperfusion injury with inhaled hydrogen or carbon monoxide, or both. J Heart Lung Transplant 2010;29:544-53.

10. Shingu C, Koga H, Hagiwara S, Matsumoto S, Goto K, Yohoi I, Noguchi T. Hydrogen-rich saline solution attenuates renal ischemia-reperfusion injury. J Anesth 20I0;24:569-74.

II. Buchholz BM, Kaczorowski DJ, Sugimoto R, Yang R, Wang Y, Billiar TR, McCurry KR, Bauer AJ, Nakao A. Hydrogen inhalation ameliorates oxidative stress in transplantation induced intestinal graft injury. Am J Transplant 2008;8:20I5-24.

12. Zhao L, Wang YB, Qin SR, Ma XM, Sun XJ, Wang ML, Zhong RG. Protective effect of hydrogen-rich saline on ischemia/reperfusion injury in rat skin flap. J Zhejiang Univ Sci B 2013; |4:382-91.

13. Wang WZ, Baynosa RC, Zamboni WA. Update on ischemia-reperfusion injury for the plastic surgeon: 20 I I. Plast Reconstr Surg 20I I; I 28:685e-92e.

14. van den Heuvel MG, Buurman WA, Bast A, van der Hulst RR. Review: ischaemia-reperfusion injury in flap surgery. J Plast Reconstr Aesthet Surg 2009;62:72I-6.

15. Harder Y, Amon M, Laschke MW, Schramm R, Rucker M, Wettstein R. An old dream revitalized: preconditioning strategies to protect surgical flaps from critical ischemia and ischaemia-reperfusion injury. J Plast Reconstr Aesthet Surg 2008;6I:503-II.

16. Karaaslan O, Ulusoy MG, Kankaya Y, Tiftikcioglu YO, Kocer U, Kankaya D, Karaaslan GM, Tuncer S, Berktas M. Protective effect of grape seed extract against ischeaemia/reperfusion injury in a rat epigastric flap model. J Plast Reconstr Aesthet Surg 2010;63:705-10.

17. Aydogan H, Gurlek A, Parlakpinar H, Askar I, Bay-Karabulut A, Aydogan N, Fariz A, Acet A. Beneficial effects of caffeic acid phenethyl ester (CAPE) on the ischemia-reperfusion injury in rat skin flaps. J Plast Reconstr Aesthet Surg 2007;60:563-8.

18. Cetin C, Kose AA, Aral E, Colak O, Ercel C, Karabağli Y, Alataș O, Eker A. Protective effect of fucoidin (a neutrophil rolling inhibitor) on ischemia reperfusion injury: experimental study in rat epigastric Island flaps. Ann Plast Surg 200 I;47:540-6.

19. Schoenberg MH, Beger HG. Reperfusion injury after intestinal ischemia. Crit Care Med 1993;21:1376-86.

20. Ozmen S, Ayhan S, Demir Y, Siemionow M, Atabay K. Impact of gradual blood flow increase on ischaemia-reperfusion injury in the rat cremaster microcirculation model. J Plast Reconstr Aesthet Surg 2008;61:939-48.

21. Chen H, Sun YP, Hu PF, Liu WW, Xiang HG, Li Y, Yan RL, Su N, Ruan CP, Sun $X J$, Wang $Q$. The effects of hydrogen-rich saline on the contractile and structural changes of intestine induced by ischemia-reperfusion in rats. J Surg Res 2011;167:316-22.

22. Imai S, Kozai H, Matsuda M, Hasegawa G, Obayashi H, Togawa C, Yamamura T, Watanabe K, Miyatani S, Yoshikawa T, Kajiyama S. Intervention with delivery of diabetic meals improves glycemic control in patients with type 2 diabetes mellitus. J Clin Biochem Nutr 2008;42:59-63.

23. Nakayama M, Nakano $H$, Hamada $H$, Itami $N$, Nakazawa R, Ito S. A novel bioactive haemodialysis system using dissolved dihydrogen $(\mathrm{H} 2)$ produced by water electrolysis: a clinical trial. Nephrol Dial Transplant 2010;25:3026-33.

24. Ito $M$, Ibi T, Sahashi K, Ichihara M, Ito M, Ohno K. Open-label trial and randomized, double-blind, placebo-controlled, crossover trial of hydrogen-enriched water for mitochondrial and inflammatory myopathies. Med Gas Res 20I I; I:24.

25. Kang KM, Kang YN, Choi IB, Gu Y, Kawamura T, Toyoda Y, Nakao A. Effects of drinking hydrogen-rich water on the quality of life of patients treated with radiotherapy for liver tumors. Med Gas Res 201 I; I: I I.

26. Ono H, Nishijima Y, Adachi N, Sakamoto M, Kudo Y, Nakazawa J, Kaneko K, Nakao A. Hydrogen $\left(\mathrm{H}_{2}\right)$ treatment for acute erythymatous skin diseases. A report of 4 patients with safety date and a non-controlled feasibility study with $\mathrm{H} 2$ concentration measurement on two volunteers. Med Gas Res 2012;2:14.

27. Kuntscher MV, Schirmbeck EU, Menke H, Klar E, Gebhard MM, Germann G. Ischemic preconditioning by brief extremity ischemia before flap ischemia in a rat model. Plast Reconstr Surg 2002; 109:2398-404.

28. Xue X, Piao JH, Nakajima A, Sakon-Komazawa S, Kojima Y, Mori K, Yagita $\mathrm{H}$, Okumura $\mathrm{K}$, Harding $\mathrm{H}$, Nakano $\mathrm{H}$. Tumor necrosis factor alpha (TNFalpha) induces the unfolded protein response (UPR) in a reactive oxygen species (ROS)-dependent fashion, and the UPR counteracts ROS accumulation by TNFalpha. J Biol Chem 2005;280:33917-25.

29. Schulze-Osthoff K, Bakker AC, Vanhaesebroeck B, Beyaert R, Jacob WA, Fiers W. Cytotoxic activity of tumor necrosis factor is mediated by early 
damage of mitochondrial functions. Evidence for the involvement of mitochondrial radical generation. J Biol Chem 1992;267:5317-23.

30. Goossens V, Grooten J, De Vos K, Fiers W. Direct evidence for tumor necrosis factor-induced mitochondrial reactive oxygen intermediates and their involvement in cytotoxicity. Proc Natl Acad Sci U S A 1995;92:8115-9.

31. Fernández-Checa JC, Kaplowitz N, García-Ruiz C, Colell A, Miranda M, Marí M, Ardite E, Morales A. GSH transport in mitochondria: defense against TNF-induced oxidative stress and alcohol-induced defect. Am J Physiol 1997;273:G7-17.
32. Ayatollahi SA, Ajami M, Reyhanfard H, Asadi Y, Nassiri-Kashani M, Rashighi Firoozabadi M, Davoodi SH, Habibi E, Pazodi-Toroudi H. BCL-2 and bax expression in skin flaps treated with finasteride or azelaic acid. Iran J Pharm Res 201 2; I I:I285-90.

33. Li CX, Shen SM, Wang LS, Yu Y. Caspase-3-resistant uncleavable form of acidic leucine-rich nuclear phosphoprotein 32B potentiates leukemic cell apoptosis. Mol Med Rep 2015; I :2813-8.

34. Gharib B, Hanna S, Abdallahi OM, Lepidi H, Gardette B, De Reggi M. Anti-inflammatory properties of molecular hydrogen: investigation on parasite-induced liver inflammation. C RAcad Sci III 200I;324:719-24. 